\title{
Efeito da Inclusão do Farelo e da Farinha de Semente de Algodão em Rações para Reprodutores de Tilápia do Nilo (Oreochromis niloticus) ${ }^{1}$
}

\author{
Ana Lúcia Salaro², Luiz Edivaldo Pezzato ${ }^{3}$, Carlos Alberto Vicentini ${ }^{4}$, Margarida Maria Barros ${ }^{5}$
}

\begin{abstract}
RESUMO - Este experimento foi realizado para avaliar o efeito do farelo e da farinha de algodão no comportamento reprodutivo e na atividade testicular de reprodutores de tilápia do Nilo. Vinte e cinco peixes receberam dietas contendo $0 ; 2 ; 4$; e $6 \%$ de semente de algodão descorticada e moída e $24,0 \%$ de farelo de algodão. O comportamento reprodutivo foi observado e a construção de ninhos, corte e desova, avaliadas. Aos 90 dias, as gônadas dos machos foram avaliadas microscopicamente. O grupo controle (farelo de algodão) obteve maior número de desovas. Os peixes alimentados com semente ou farelo de algodão, apesar de não terem apresentado o mesmo número de desovas, construíram ninhos e fizeram a corte. A análise histológica dos testículos demonstrou que a adição de $24,0 \%$ de farelo ou níveis de $2,0 \%$ ou superiores da farinha influiu na atividade testicular. O gossipol presente na farinha ou farelo de algodão teve efeito negativa nas gônadas destes animais.
\end{abstract}

Palavras-chave: comportamento reprodutivo, espermatogênese, farelo de algodão, gossipol, semente de algodão, sistema reprodutor, tilápia do Nilo

\section{Effect of Adding Cottonseed Meal or Cottonseed Flour to Rations for Nile Tilapia (Oreochromis niloticus) Broodstock}

\begin{abstract}
This experiment was conducted to evaluate the effect of cottonseed meal and cotton seed flour on the reproductive behavior and on the testis activity of Nile tilapia broodstock. Twenty-five fishes were fed diets containing $0,2,4$ and $6 \%$ ground cottonseed flour and $24 \%$ cottonseed meal (CSM). The reproductive behavior of the fishes was daily observed and the nest construction, courtship and spawning were evaluated. At 90 days, the males gonads were microscopically evaluated. The control group (soybean meal) showed higher number of spawning. The fishes fed diets with cottonseed flour or cottonseed meal, despite of had not presented the same number of spawning, showed nest construction and courtship. The histology analysis of the testis indicated that the addition of $24 \%$ of cottonseed meal or $2 \%$ or higher of cottonseed flour affected the testis activity. The gossypol present in the cottonseed flour or cottonseed meal had a negative effect on the gonads of these animals.
\end{abstract}

Key Words: reproductive behavior, spermatogenesis, cottonseed meal, gossypol, cotton seed flour, reproductive system, Nile tilapia

\section{Introdução}

A fim de obter dietas mais econômicas, o farelo de algodão tem sido utilizado como fonte protéica sucedânea, em rações para peixes tropicais. Para tanto, é submetido a tratamento com óxido férrico, a fim de minimizar a ação do gossipol presente no produto. Vários criadores vêm empregando a semente de algodão na formulação de dietas, embora as conseqüências desta prática não estejam ainda bem definidas.

O estudo dos efeitos antinutricionais do gossipol sobre a reprodução de várias espécies de monogástricos vem causando grande interesse entre os pesquisadores. Efeitos deletérios sobre a motilidade espermática e a espermatogênese vêm sendo registrados na literatura. Entre os aspectos negativos observados em várias espécies, encontram-se a diminuição da motilidade e do número de espermatozóides e, ainda, a imaturidade dos mesmos (RUTLE, 1989).

CHASE et al. (1990) definiram que estes problemas reprodutivos são conseqüência da degeneração do tecido testicular, que implica em diminuição do número de espermatozóides que atingiriam maturação e aumento da porcentagem de espermatozóides anormais. RANDEL et al. (1990) verificaram que animais recebendo dietas com níveis diferenciados de gossipol apresentavam imotilidade e diminuição no número de espermatozóides, além de danos no epitélio

\footnotetext{
${ }^{1}$ Parte da Tese de Doutorado do primeiro autor.

${ }^{2}$ Bióloga - Prof. Dep. de Biologia Animal - UFV - 36571-000 - Viçosa - MG. E-mail: salaro@mail.ufv.br

${ }^{3}$ Zootecnista, Dr., FMVZ - UNESP, Campus de Botucatu - CEP 18618-000 - Caixa Postal 560.

${ }^{4}$ Biólogo, Dr., Dep. de Morfologia - IB/UNESP, Campus de Bauru.

${ }^{5}$ Zootecnista, Dr., FMVZ - UNESP, Campus de Botucatu.
} 
1170

germinativo, acarretando diminuição no processo de espermatogênese.

Embora existam poucas investigações sobre a ação do gossipol em peixes, infere-se, com base na ação deste sobre o sistema reprodutor das demais espécies animais, que este possa causar prejuízos ao desempenho reprodutivo de peixes. Este efeito considerado negativo para muitas espécies poderia contribuir de forma positiva, especificamente no caso da tilápia do Nilo, por diminuir a reprodução durante o período de engorda. Com base no exposto, este experimento teve como objetivo conhecer e avaliar o efeito do gossipol presente na farinha de semente e no farelo de algodão, por intermédio do estudo do comportamento reprodutivo e da análise histológica dos testículos da tilápia do Nilo (Oreochromis niloticus).

\section{Material e Métodos}

Este experimento foi realizado nos Laboratórios de Nutrição de Peixes do Departamento de Melhoramento e Nutrição Animal (FMVZ - UNESP - Campus de Botucatu) e do Departamento de Morfologia da Faculdade de Ciências Biológicas de Bauru UNESP (Laboratórios Associadas ao Centro de Aqüicultura da UNESP).

Lotes homogêneos de três fêmeas e dois machos de tilápia do Nilo, com peso médio de 45,0 gramas, foram distribuídos em cinco aquários de $750 \mathrm{~L}(110 \mathrm{x}$ 110 x $65 \mathrm{~cm}$ ), com sistema de renovação contínuo de água, com fluxo de aproximadamente $1 \mathrm{~L} / \mathrm{min}$. Os aquários contaram com sistema de iluminação artificial $\left(12\right.$ horas/dia) e temperatura controlada $\left(28^{\circ} \mathrm{C}\right)$.

Os peixes foram sexados e selecionados previamente utilizando-se os caracteres sexuais secundários, como coloração avermelhada das nadadeiras peitorais e caudal nos machos, papila genital bem desenvolvida em ambos os sexos e abaulamento do ventre nas fêmeas. Os reprodutores foram submetidos a uma fase de aclimatação em condições idênticas às da fase experimental, recebendo ração comercial por um período de 15 dias.

Os peixes foram alimentados com dietas isoprotéicas (28\% PB) e isoenergéticas (4030 kcal/EB/kg/ração), balanceadas segundo as normas apresentadas pelo NATIONAL ACADEMY OF SCIENCE - NAS (1993), constituindo cinco tratamentos: 0 (controle), 2, 4 e $6 \%$ de semente descorticada de algodão moída e $24 \%$ de farelo de algodão, denominados tratamentos 0-SA, 2-SA, 4-SA, 6-SA e 24-FA (Tabela 1). O farelo de algodão utilizado foi proveniente da extra-
SALARO et al.

ção com solvente hexana, e a semente descorticada não foi submetida a tratamento. $\mathrm{O}$ tratamento 24-FA baseia-se nos resultados obtidos por BARROS et al. (1995). Na confecção das rações, os ingredientes foram homogeneizados em um moinho de disco com peneira de abertura de $0,42 \mathrm{~mm}$, misturados em um misturador do tipo "Y" e granulados em uma prensa industrial. Os ingredientes foram analisados no Laboratório de Bromatologia do Departamento de Melhoramento e Nutrição Animal (FMVZ), UNESP, Campus de Botucatu (Tabela 2), segundo as normas recomendadas pela ASSOCIATION OIL CHEMIST'S SOCIETY - AOCS (1967) e ASSOCIATION OF OFFICIALANALYTICALCHEMISTS - AOAC (1975).

A temperatura da água dos aquários foi monitorada diariamente, às 9 e $15 \mathrm{~h}$, enquanto a avaliação das condições químicas foram realizadas quinzenalmente, determinando-se $\mathrm{pH}$ e oxigênio dissolvido. Os peixes foram alimentados ad libitum diariamente logo após a aferição da temperatura da água. Em seguida, os lotes foram observados por 15 minutos com o objetivo de avaliar o comportamento reprodutivo, que, segundo LILEY e STACEY (1983), em espécies de reprodução externa, se divide em duas etapas: comportamento de pré-desova e desova. Assim, foram observadas as atividades de tempo de início para construção dos ninhos, corte e desova. Os registros acima citados foram coletados sempre no mesmo horário, $9 \mathrm{~h} 30$ e $16 \mathrm{~h} 30$, tentando-se minimizar os efeitos das variações circadianas nas atividades dos animais.

Duas vezes por semana, as fêmeas eram retiradas das caixas e submetidas ao exame de ocorrência de desovas, onde se procedia à retirada dos ovos da boca das mesmas com auxílio de pisseta contendo água destilada. Este procedimento foi realizado nos machos para que estes também passassem pelo mesmo estresse aplicados às fêmeas. Antes da devolução dos peixes às caixas, estas eram sifonadas para retirada dos possíveis ovos lançados pelas fêmeas no momento da captura e, também, para retirar restos de alimentos e excretas não-carreados pelo sistema de renovação de água.

Ao final do experimento, os machos foram sacrificados e seus testículos, fixados com solução de Bouin e incluídos em parafina. Cortes de $7 \mathrm{~mm}$ foram corados com hematoxilina/eosina (H/E) de acordo com metodologia recomendada por LUNA (1968). Para a caracterização da atividade testicular, foi realizado o diagnóstico do estádio de maturação gonadal, em função dos tipos de células germinativas 
Tabela 1 - Composição percentual estimada dos ingredientes e características nutritivas das rações experimentais

Table 1 - Estimated percentage composition of the ingredients and nutritional characteristic of the experimental diets

\begin{tabular}{|c|c|c|c|c|c|}
\hline \multirow[t]{2}{*}{$\begin{array}{l}\text { Ingrediente } \\
\text { Ingredient }\end{array}$} & \multicolumn{4}{|c|}{$\begin{array}{c}\text { Tratamento } \\
\text { Treatment }\end{array}$} & \multirow[b]{2}{*}{ 24-FA } \\
\hline & $0-\mathrm{SA}$ & 2-SA & 4-SA & 6-SA & \\
\hline Fubá de milho & 38,17 & 38,50 & 38,78 & 39,44 & 36,06 \\
\hline Corn meal & & & & & \\
\hline $\begin{array}{l}\text { Farelo de soja } \\
\text { Soybean meal }\end{array}$ & 48,16 & 46,65 & 45,14 & 43,56 & 28,27 \\
\hline Farinha de semente de algodão & - & 2,00 & 4,00 & 6,00 & - \\
\hline $\begin{array}{l}\text { Cottonseed flour } \\
\text { Farelo de algodão }\end{array}$ & - & - & - & - & 24,00 \\
\hline $\begin{array}{l}\text { Cottonseed meal } \\
\text { Farinha de peixe } \\
\text { Fish meal }\end{array}$ & 5,00 & 5,00 & 5,00 & 5,00 & 5,00 \\
\hline $\begin{array}{l}\text { Amido de milho } \\
\text { Corn starch }\end{array}$ & 5,00 & 5,00 & 5,00 & 5,00 & 5,00 \\
\hline $\begin{array}{l}\text { Óleo de soja } \\
\text { Soybean oil }\end{array}$ & 0,92 & 0,70 & 0,50 & - & 0,40 \\
\hline $\begin{array}{l}\text { Casca de arroz } \\
\text { Rice bran }\end{array}$ & 1,75 & 1,15 & 0,58 & - & 0,27 \\
\hline $\begin{array}{l}\text { Premix (vitaminas e minerais) } \\
\text { Premix (vitamin and mineral) }\end{array}$ & 1,00 & 1,00 & 1,00 & 1,00 & 1,00 \\
\hline $\begin{array}{l}\text { Proteína bruta (\%) } \\
\text { Crude protein }\end{array}$ & 28,00 & 28,00 & 28,00 & 28,00 & 28,00 \\
\hline $\begin{array}{l}\text { Fibra bruta }(\%) \\
\text { Crude fiber }\end{array}$ & 5,48 & 5,47 & 5,49 & 5,50 & 5,49 \\
\hline $\begin{array}{l}\text { Extrato etéreo (\%) } \\
\text { Ether extract }\end{array}$ & 3,02 & 3,58 & 4,17 & 4,42 & 2,33 \\
\hline $\begin{array}{l}\text { Energia bruta }(\mathrm{kcal} / \mathrm{kg} \bullet \text { ração) } \\
\text { Gross energy }\end{array}$ & 4012 & 4030 & 4052 & 4058 & 4039 \\
\hline $\mathrm{Ca}(\%)$ & 0,48 & 0,48 & 0,48 & 0,48 & 0,47 \\
\hline $\mathrm{P}(\%)$ & 0,27 & 0,27 & 0,27 & 0,28 & 0,29 \\
\hline
\end{tabular}

presentes nas gônadas dos animais, com base nos trabalhos de ALEXANDRINO et al. (1985), GONÇALVES (1993), CAVALCANTI (1994) e NARAHARA (1995).

\section{Resultados e Discussão}

\section{Comportamento reprodutivo}

Os resultados obtidos quanto ao tempo, para início da construção de ninhos, corte e desova, foram agrupados didaticamente em três períodos, de 07/03 a 07/04 (primeiro período), 08/04 a 07/05 (segundo período) e 08/05 a 07/06 (terceiro e último período). No primeiro período, sinais comportamentais reprodutivos relacionados à construção de ninhos ocorreram apenas nos grupos controle e 24-FA, sendo observados aos 21 dias após o início do experimento. Novos ninhos foram observados no grupo 24-FA aos 22 dias, não sendo registrada ocorrência de ninhos nos demais grupos (Tabela 3). A desova ocorreu dois dias após o registro dos ninhos, tanto no grupo controle como no grupo 24-FA. Embora não tenham sido detectados ninhos nos demais grupos, foram retirados ovos em uma das fêmeas do grupo 6-SA, indicando ocorrência de desova aos 27 dias (Tabela 3 ).

De acordo com estas observações, pode-se inferir que o período de um mês não tenha sido suficiente para ação dos tratamentos, e sim para que os peixes já estivessem preparados para desova necessitando apenas melhores condições como temperatura ou luminosidade, encontradas neste experimento.

Observou-se formação de ninhos aos 32 dias do início do experimento ( 2 $\underline{\underline{o}}$ período) nos grupos controle e 24-FA e aos 33 dias nos tratamentos 2-SA, 4-SA e 6-SA. No decorrer deste período, novos ninhos foram construídos pelos peixes em todos tratamentos, diferindo apenas no tempo gasto por cada grupo para o início da construção (Tabela 4).

Com base nos resultados obtidos, pode-se considerar que o uso de farinha de semente ou farelo de algodão nas rações não influiu no comportamento dos animais no que se refere à construção de ninhos, uma vez que todos os grupos conseguiram construí-los, diferindo em tempo, tamanho e frequiência, com des- 
SALARO et al.

Tabela 2 - Composição químico-bromatológica dos ingredientes usados nas dietas experimentais 1

Table 2 - Chemical-bromatological composition of the ingredients used in the experimental diets

\begin{tabular}{|c|c|c|c|c|c|c|}
\hline $\begin{array}{l}\text { Ingrediente } \\
\text { Ingredient }\end{array}$ & $\begin{array}{c}\mathrm{PB}(\%) \\
C P\end{array}$ & $\mathrm{FB}(\%)$ & $\mathrm{EE}(\%)$ & $\mathrm{EB}^{(2)}$ & $\mathrm{Ca}(\%)$ & $\operatorname{Pd}(\%)$ \\
\hline Fubá de milho & 8,61 & 1,80 & 3,30 & 3950 & 0,02 & 0,09 \\
\hline $\begin{array}{l}\text { Corn meal } \\
\text { Farelo de soja }\end{array}$ & 45,30 & 6,30 & 1,10 & 4187 & 0,36 & 0,18 \\
\hline $\begin{array}{l}\text { Soybean oil } \\
\text { Farinha de semente de algodão } \\
\text { Cottonseed flour }\end{array}$ & 32,90 & 33,98 & 38,91 & 4630 & 0,30 & 0,32 \\
\hline $\begin{array}{l}\text { Farelo de algodão } \\
\text { Cottonseed meal }\end{array}$ & 38,20 & 11,60 & 0,92 & 4140 & 0,28 & 0,26 \\
\hline $\begin{array}{l}\text { Farinha de peixe } \\
\text { Fish meal }\end{array}$ & 57,42 & 0,22 & 6,00 & 4344 & 6,00 & 3,00 \\
\hline $\begin{array}{l}\text { Amido de milho } \\
\text { Corn starch }\end{array}$ & 0,55 & - & 0,13 & 3631 & - & - \\
\hline $\begin{array}{l}\text { Óleo de soja } \\
\text { Soybean oil }\end{array}$ & - & - & 100,00 & 9730 & - & - \\
\hline
\end{tabular}

1 Valores expressos a $100 \%$ MS (Values express in dry matter basis).

2 Energia bruta (Gross energy), kcal/kg.

Tabela 3 - Presença de ninho e desova nos primeiros 30 dias experimentais Table 3 - Presence of nest and spawns in the first 30 of days experiment

\begin{tabular}{|c|c|c|c|c|c|c|c|c|c|c|}
\hline \multirow[t]{3}{*}{$\begin{array}{l}\text { Período (dias) } \\
\text { Period (days) }\end{array}$} & \multicolumn{10}{|c|}{$\begin{array}{c}\text { Tratamento } \\
\text { Treatment }\end{array}$} \\
\hline & \multicolumn{2}{|c|}{$\mathrm{C}^{1}$} & \multicolumn{2}{|c|}{$2-S^{2}$} & \multicolumn{2}{|c|}{ 4-SA } & \multicolumn{2}{|c|}{ 6-SA } & \multicolumn{2}{|c|}{$24-F^{3}$} \\
\hline & $\mathrm{N}^{4}$ & $\mathrm{D}^{5}$ & $\mathrm{~N}$ & $\mathrm{D}$ & $\mathrm{N}$ & $\mathrm{D}$ & $\mathrm{N}$ & $\mathrm{D}$ & $\mathrm{N}$ & $\mathrm{D}$ \\
\hline 21 & $X$ & - & - & - & - & - & - & - & $X$ & - \\
\hline 22 & - & - & - & - & - & - & - & - & $X$ & - \\
\hline 24 & - & $X$ & - & - & - & - & - & - & - & $X$ \\
\hline 27 & - & - & - & - & - & - & - & $\mathrm{X}$ & - & - \\
\hline Total & 1 & 1 & 0 & 0 & 0 & 0 & 0 & 1 & 2 & 1 \\
\hline
\end{tabular}

\footnotetext{
${ }^{1}$ Controle (Control).

2 Semente de algodão (Cottonseed)

3 Farelo de algodão (Cottonseed meal).

4 Nidificação (Nest).

${ }^{5}$ Desova (Spawns).
}

taque para o grupo 6-SA, no qual os ninhos foram menos freqüentes (Tabela 4) e de menor tamanho.

O grupo controle, apesar de não ter sido o grupo em que ocorreu maior freqüência em número de ninhos, teve o maior índice de desova, quando comparado com os demais grupos-teste, totalizando seis desovas versus duas desovas nos demais, com exceção do grupo que recebeu $4 \%$ de semente de algodão (4-SA), no qual não ocorreram desovas neste período (Tabela 4). De posse destes resultados, pode-se deduzir que o algodão causou atraso no ciclo reprodutivo, ou mesmo produziu alterações nas gônadas da tilápia do Nilo.
No terceiro e último período, houve repetição do exposto acima, em que ninhos foram detectados em todos os tratamentos, acentuando-se a diferença no tempo gasto para o início da construção dos mesmos (Tabela 5). As desovas ocorridas neste período foram também mais freqüentes no grupo controle em comparação aos demais. Neste período, observaram-se, também, uma desova nos tratamentos 24-FA e uma no 4-SA, sendo esta a primeira ocorrida neste grupo, e nenhuma desova no tratamento 6-SA. Acrescido a isto, as desovas do grupo controle ocorreram antes dos demais tratamentos, indicando provável atraso no processo reprodutivo destes animais, quan- 
Rev. bras. zootec.

Tabela 4 - Presença de ninho e desova dos 30 aos 60 dias experimentais

Table 4 - Presence of nest and spawns from 30 to 60 of experimental days

Período (dias) Tratamento

Period (days)

Treatment

\begin{tabular}{|c|c|c|c|c|c|c|c|c|c|c|}
\hline & \multicolumn{2}{|c|}{$\mathrm{C}^{1}$} & \multicolumn{2}{|c|}{$2-\mathrm{SA}^{2}$} & \multicolumn{2}{|c|}{ 4-SA } & \multicolumn{2}{|c|}{ 6-SA } & \multicolumn{2}{|c|}{$24-\mathrm{FA}^{3}$} \\
\hline & $\mathrm{N}^{4}$ & $\mathrm{D}^{5}$ & $\mathrm{~N}$ & $\mathrm{D}$ & $\mathrm{N}$ & $\overline{\mathrm{D}}$ & $\mathrm{N}$ & $\mathrm{D}$ & $\mathrm{N}$ & $\mathrm{D}$ \\
\hline 32 & $X$ & - & - & - & - & - & - & - & $X$ & - \\
\hline 33 & - & $X$ & X & - & X & - & $X$ & - & - & - \\
\hline 34 & - & X & - & $X$ & - & - & - & - & - & $X$ \\
\hline 36 & $X$ & - & - & $\mathrm{X}$ & $X$ & - & X & $X$ & - & - \\
\hline 38 & - & $X$ & - & - & - & - & - & - & - & - \\
\hline 41 & - & - & - & - & - & - & - & $X$ & - & $X$ \\
\hline 43 & - & - & X & - & X & - & - & - & - & - \\
\hline 44 & - & - & $X$ & - & X & - & $X$ & - & $X$ & - \\
\hline 48 & - & $X$ & - & - & - & - & - & - & - & - \\
\hline 51 & X & - & X & - & X & - & - & - & $X$ & - \\
\hline 52 & - & X & - & - & - & - & - & - & - & - \\
\hline 56 & - & $X$ & X & - & - & - & - & - & $X$ & - \\
\hline 59 & - & - & - & - & - & - & - & - & X & - \\
\hline 60 & X & - & $X$ & - & $X$ & - & - & - & $\mathrm{X}$ & - \\
\hline Total & 4 & 6 & 6 & 2 & 6 & 0 & 3 & 2 & 6 & 2 \\
\hline
\end{tabular}

${ }^{1}$ Controle (Control).

2 Semente de algodão (Cottonseed).

${ }^{3}$ Farelo de algodão (Cottonseed meal).

4 Nidificação (Nest).

5 Desova (Spawns).

Tabela 5 - Presença de ninho e desova dos 60 aos 90 dias experimentais Table 5 - Presence of nest and spawns from 60 to 90 of experimental days

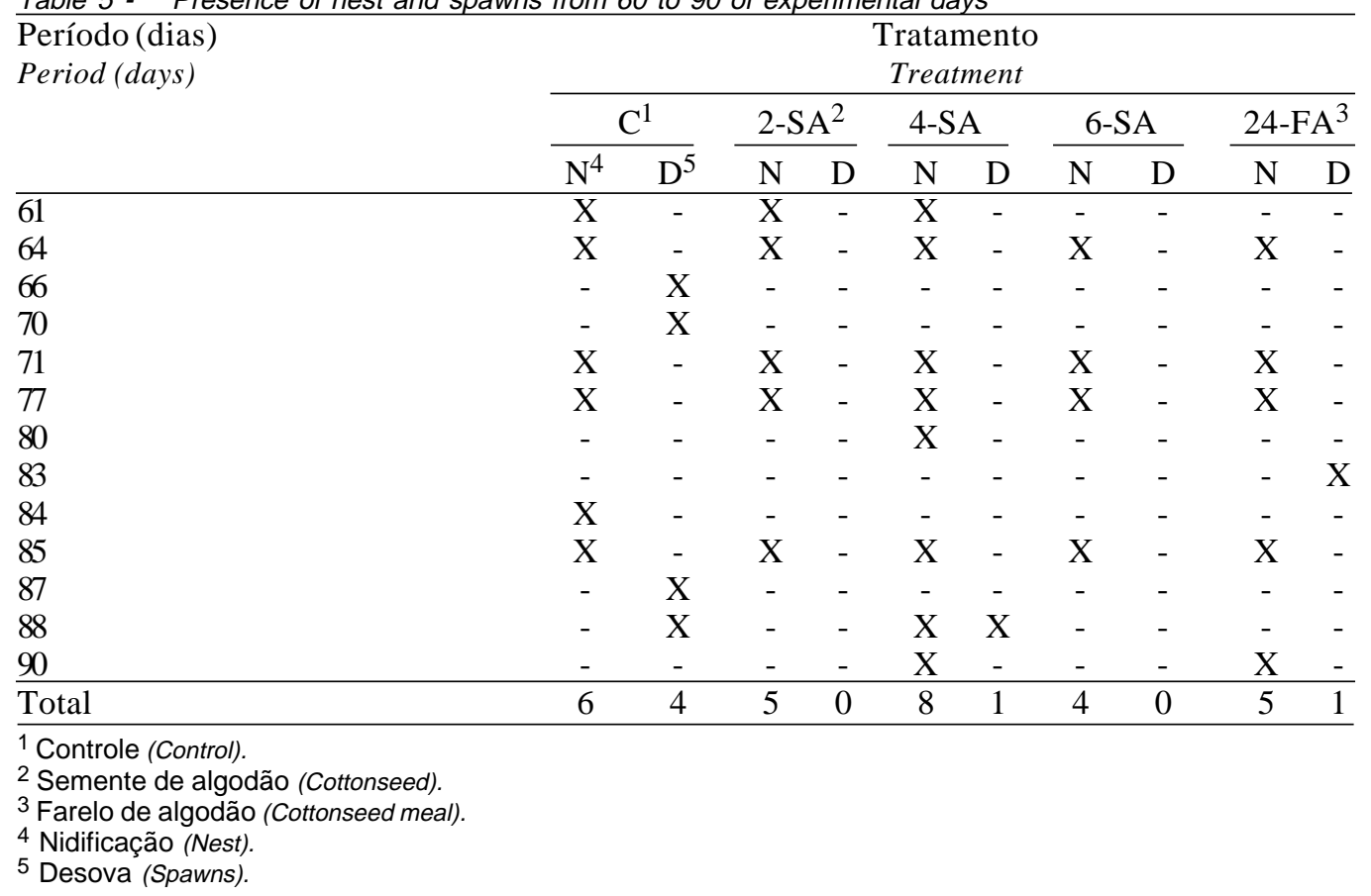

do alimentados com farelo ou semente de algodão.

Constata-se que o gossipol presente no farelo ou farinha de semente pode ter influenciado o comportamento reprodutivo da tilápia do Nilo, quando se analisa a presença de ninhos e desova dos animais, uma vez que o grupo controle teve maior freqüência de desova, embora nem sempre acompanhada pelo maior número de ninhos registrados.

Conforme observado no segundo período experimental, e destacadamente no terceiro, existiu dimi- 
SALARO et al.

Tabela 5 - Presença de ninho e desova do início ao final do experimento

Table 5 - Presence of nest and spawns from the begning to the end of the experiment

\begin{tabular}{|c|c|c|c|c|c|c|c|c|c|c|}
\hline \multirow[t]{3}{*}{$\begin{array}{l}\text { Período (dias) } \\
\text { Period (days) }\end{array}$} & \multicolumn{10}{|c|}{$\begin{array}{c}\text { Tratamento } \\
\text { Treatment }\end{array}$} \\
\hline & \multicolumn{2}{|c|}{$\mathrm{C}^{1}$} & \multicolumn{2}{|c|}{$2-\mathrm{SA}^{2}$} & \multicolumn{2}{|c|}{ 4-SA } & \multicolumn{2}{|c|}{ 6-SA } & \multicolumn{2}{|c|}{$24-\mathrm{FA}^{3}$} \\
\hline & $\mathrm{N}^{4}$ & $\mathrm{D}^{5}$ & $\mathrm{~N}$ & $\mathrm{D}$ & $\mathrm{N}$ & $\mathrm{D}$ & $\mathrm{N}$ & $\mathrm{D}$ & $\mathrm{N}$ & $\mathrm{D}$ \\
\hline 0 a 30 & 1 & 1 & 0 & 0 & 0 & 0 & 0 & 1 & 2 & 1 \\
\hline 30 a 60 & 4 & 6 & 6 & 2 & 6 & 0 & 3 & 2 & 6 & 2 \\
\hline 60 a 90 & 6 & 4 & 5 & 0 & 8 & 1 & 4 & 0 & 5 & 1 \\
\hline Total (0 a 90) & 11 & 11 & 11 & 2 & 14 & 1 & 7 & 3 & 13 & 4 \\
\hline
\end{tabular}

1 Controle (Control).

2 Semente de algodão (Cottonseed).

3 Farelo de algodão (Cottonseed meal).

4 Nidificação (Nest).

5 Desova (Spawns).

nuição no número de desovas nos tratamentos que continham farelo ou semente de algodão. Estes fato demonstra a ação do gossipol de forma crescente, em função da dose e do tempo de alimentação. Este resultados confirmam os trabalhos realizados com ruminantes feitos por RANDEL et al. (1990, 1992), no qual é destacado o efeito sinérgico entre dose e tempo de ingestão do gossipol.

No decorrer de todo o experimento, verificou-se comportamento de corte em todos os grupos, indicando que o gossipol não influiu no comportamento reprodutivo, mas, provavelmente, na fisiologia reprodutiva. Estes resultados concordam com os obtidos pelo NATIONAL COORDINATING GROUP ON MALE ANTIFERTILY AGENTS (1978), quando ratos alimentados com dietas contendo gossipol não apresentaram diferença com relação à libido.

\section{Análise microscópica dos testículos}

A análise microscópica dos testículos do grupo controle (0-SA) indicou que estes se apresentaram em fase de intensa atividade espermatogênica, predominando cistos de espermatócitos, espermátides e muitos espermatozóides na luz dos túbulos (Figura 1). Neste grupo, ocorreu maior homogeneidade entre as fases do processo de espermatogênese, em que as células germinativas se encontraram no mesmo estádio de desenvolvimento no interior do cistos germinativos. Estes resultados confirmam as observações microscópicas realizadas por van TIENHOVEN (1983), em peixes teleósteos, os quais apresentaram células germinativas no mesmo estádio de amadurecimento no interior dos cistos germinativos, sendo estas características também observadas por SILVA (1987) para a tilápia do Nilo.

A análise microscópica realizada nas gônadas dos peixes do tratamento 24-FA apresentou resulta- do semelhante ao observado no grupo 0-SA. Entretanto, constatou-se aumento de tecido intersticial, o que caracteriza provável alteração morfológica.

Com relação ao tratamento 2-SA, observou-se aumento de tecido intersticial (Figura 2) similar ao do grupo 24-FA, que, como já citado, é indício de efeito da presença de gossipol na dieta. Efeito de tratamento foi destacadamente constatado nas gônadas dos indivíduos submetidos aos tratamentos 4-SA e 6-SA. No tratamento 4-SA, observou-se aumento ainda maior de tecido intersticial, quando comparado aos tratamentos 2-SA e 24-FA (Figuras 2 e 3).

As gônadas dos peixes do grupo 6-SA (Figura 4) revelaram, de forma mais acentuada, a ação do gossipol no processo de atividade testicular, caracterizada pelo aumento de tecido intersticial. Assim, o gossipol influenciou a atividade testicular, provocando aumento do tecido intersticial de forma crescente, de acordo com os níveis de farelo ou semente de algodão presente nas dietas.

Cabe destacar que outras alterações morfológicas foram observadas em monogástricos e ruminantes jovens, como aumento do diâmetro do lume testicular, menor número das camadas celulares, diminuição e danificação do epitélio germinativo dos túbulos seminíferos, além de diminuição de tamanho e alterações morfológicas das células de Sertoli e Leydig (ARSHAMI e RUTLE, 1989; RANDEL et al., 1990 e 1992). Segundo esses autores, outras alterações observadas com relação ao sistema reprodutor dos animais incluem imotilidade dos espermatozóides e diminuição do número de espermatozóides normais, chegando mesmo à condição de oligospermia ou azoospermia. Em alguns casos, a presença do gossipol pode interferir em todo o ciclo de espermatogênese. 


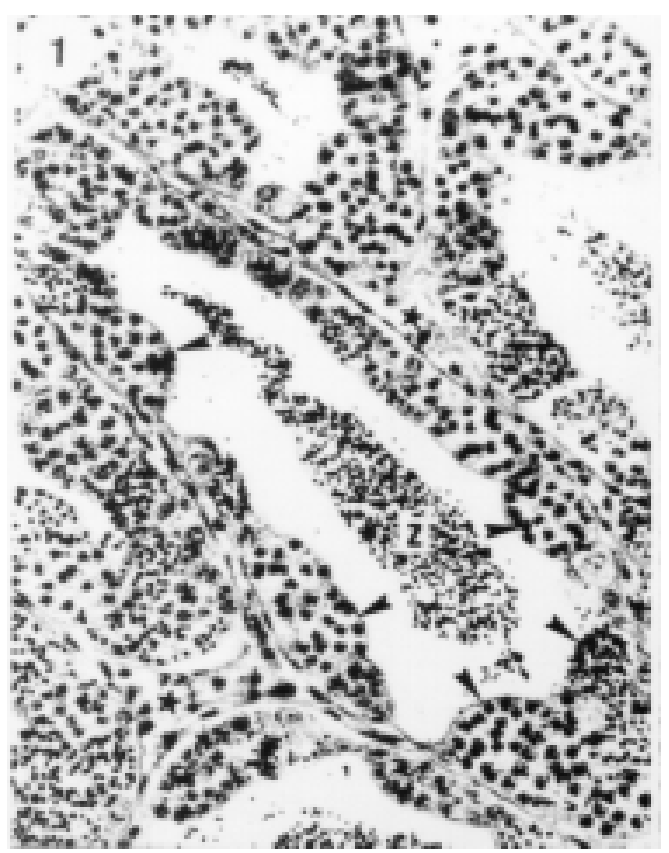

Figura 1 - Testículos de reprodutores de tilápia do Nilo (Oreochromis niloticus). Túbulos seminíferos contendo cistos de células germinativas (cabeça de seta), espermatozóides livres (z) e tecido intersticial (estrelas), (H/E, 200X).

Figure 1 - Testis of broodstock Nile tilapia (Oreochromis niloticus). Seminiferous tubules containing cist of the germinative cells (arrow head), free spermatozoid ( $z$ ) and intersticial tissue (stars), (H/E, 200X).

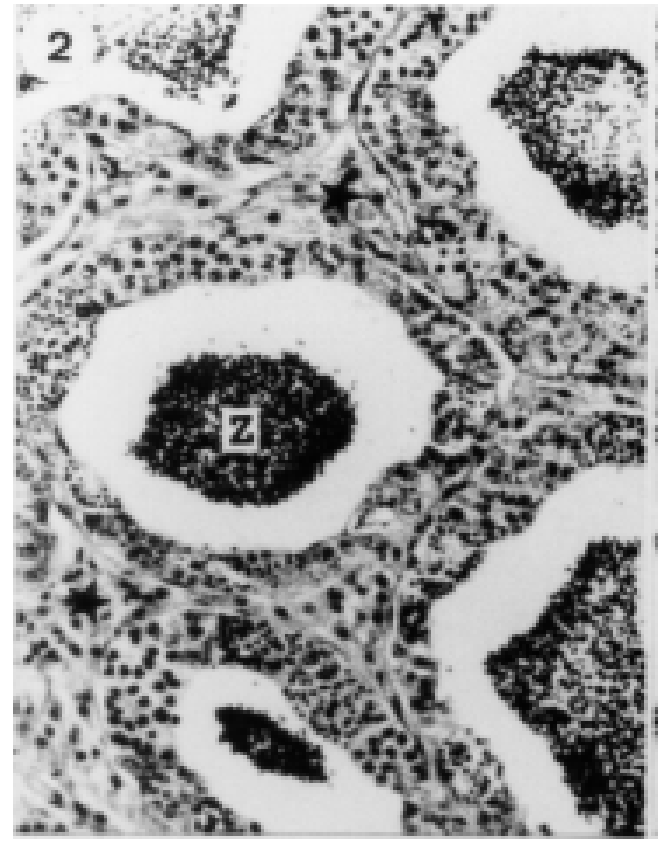

Figura 2 - Testículo de reprodutores de tilápia do Nilo (2SA). Túbulos seminíferos contendo espermatozóides livres (z) com aumento de tecido intersticial (estrelas), (H/E,200X).

Figure 2 - Testis of broodstock Nile tilapia (2-SA). Seminiferous tubule containing free spermatozoid ( $z$ ) with increase in the intersticial tissue (stars), (H/E, 200X).

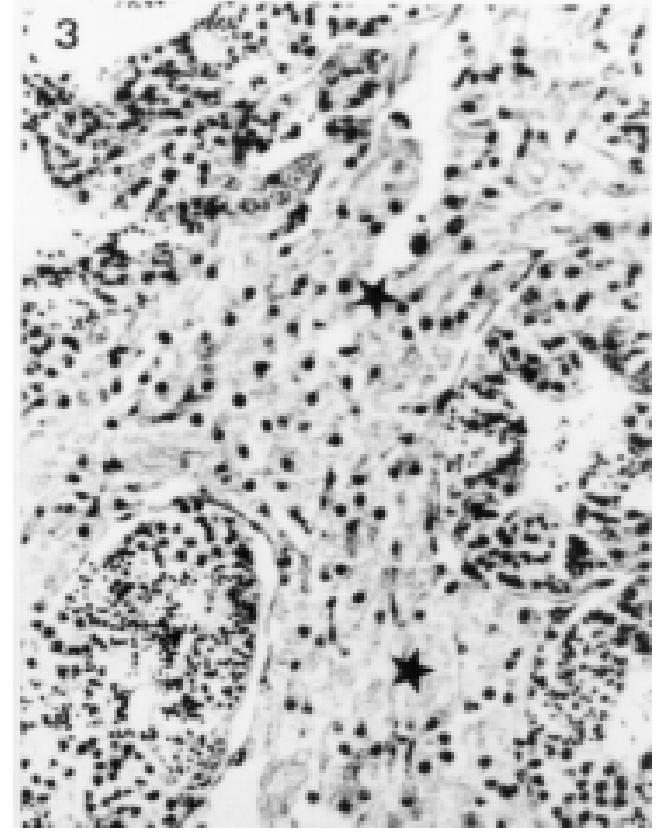

Figura 3 - Testículo de reprodutores de tilápia do Nilo (4SA), enfatizando aumento de tecido intersticial (estrelas),(H/E, 200X).

Figure 3 - Testis of broodstock Nile tilapia (4-SA), emphasizing the increase in intersticial tissue (stars), (H/E, 200X).

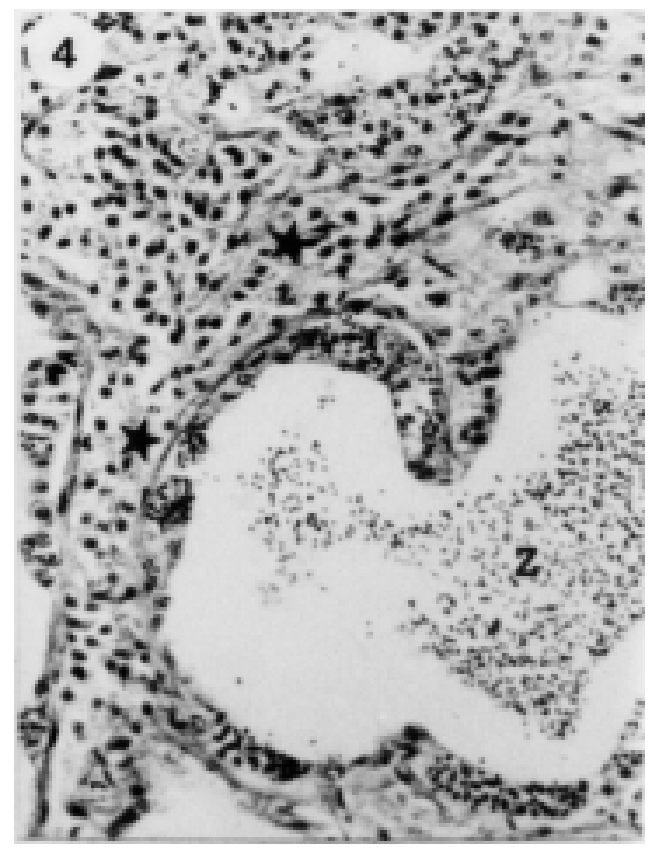

Figura 4 - Testículo de reprodutores de tilápia do Nilo (6SA). Espermatozóides livres no lume tubular ( $\mathrm{z}$ ) e tecido intersticial aumentado (estrelas), (H/E, 200X).

Figura 4 - Testis of broodstock Nile tilapia (6-SA). Free spermatozoid in the tubulous lume $(z)$ and increased intersticial tissue (stars), (H/E, 200X). 


\section{Conclusões}

O gossipol presente no farelo ou semente de algodão influiu na fisiologia reprodutiva da tilápia do Nilo, mas não influenciou o comportamento de corte e a nidificação da espécie.

O emprego de níveis de semente de algodão superior a $2 \%$ na dieta de reprodutores de tilápia do Nilo interfiu na atividade testicular da espécie, provocando aumento acentuado de tecido intersticial.

\section{Referências Bibliográficas}

ALEXANDRINO, A.C., PHAN, N.T., PINHEIRO, E.F.G. 1985. Caracterização macroscópica das gônadas de curimbatá, Prochilodus scrofa (STEINDACHNER, 1881), durante o ciclo reprodutivo. Bol. Zool., 9:159-75.

ARSHAMI, J., RUTLE, J.L. 1989. Effects of diets containing cottonseed meal on semen qualitty and testicular tissue in fine wool rams. Proceedings Western Section Amer. Soc. Anim. Sci. and Western Branch Can. Soc. Anim. Sci., 40:277-9.

ASSOCIATION OF OFFICIAL ANALYTICAL CHEMISTS AOAC. 1975. Official methods of analysis. 12.ed. Washington. $1015 \mathrm{p}$

ASSOCIATION OIL CHEMIST'S SOCIETY- AOCS. 1967. Official and tentative methods of the american oil chemist's society. 3.ed. Cincinaty.

BARROS, M.M., SILVEIRA, AIC., PEZZATO, L.E. Efeitos do farelo de algodão, como sucedâneo protéico, sobre o desempenho de alevinos de carpa (Cyprinus carpio, L). In: CONGRESSO BRASILEIRO DE AQUICULTURA, 7, Peruíbe. Anais... Peruíbe: ACIESP, 1995, 84, p.23-9.

CAVALCANTI, D.G. Reprodução do cascudo cinza Liposarcus anisitsi (Holmberg, 1893) (Loricariidae, Siluriformes): Histologia de gônadas efatores abióticos. Jaboticabal: UNESP, 1994. 124p. Dissertação (Mestrado) - Faculdade de Ciências Agrárias e Veterinárias, Universidade Estadual Paulista, 1994.

CHASE, C.C., ARSHAMI JR., J., RUTLE, J.L. et al. 1990. Histological characteristics of testes from Brahman bulls fed diets containing gossypol. J. Anim. Sci., 68:14 (suppl.1).
Recebido em: 06/04/98 Aceito em: 24/06/99
GONÇALVES, E. Estratégias territoriais e reprodutivas da Tilápiado-Nilo (Oreochromis niloticus), Botucatu: UNESP, 1993. 147p. Dissertação (Mestrado em Zoologia) - Instituto de Biociências - Universidade Estadual Paulista, 1993.

LILEY, N.R., STACEY, N.E. 1983. Hormones, pherormones, and reproductive behavior in fish. In: HOAR, W.S., RANDAL, D.J., DONALDSON, E.M. ( Eds.) Fish fisiology. p.1-63.

LUNA, G.L. 1968. Manual of histologic staning methods of the Armed Forces Institute of pathology. New York: M.C. GrawHill. 258p.

NARAHARA, M.Y. 1995. Histologia das Gônadas de Teleósteos. In :__. Histologia de peixes. Botucatu: Faculdade de Ciências Agrárias e Veterinária, p.11-25.

NATIONAL ACADEMY OF SCIENCE - NAS. 1993. Nutrient requirements of warmwater fish. Washington. p.102.

NATIONAL COORDINATING GROUP ON MALE ANTIFERTILITY AGENTS. 1978. Gossypol - a new antifertility agent for males. Chin. Med. J., 4:417.

RANDEL, R.D., CHASE JR., C.C., WYSE, S.J. 1992. Effects of gossypol and cottonseed products on reproduction of mammals. J. Anim. Sci., 70:1628-38.

RANDEL, R.D., CHASE JR., C.C., WYSE, S.J. 1990. Effects of gossipol on reproduction in domestic livestock species. $J$. Anim. Sci., 68:405 (suppl. 1).

RUTLE, J.L. 1989. Gossypol and ruminant reproductive effects. Presentation to the Research and Education Commite of National Cottonseed Products Ass, Sept 28-29, Phoenix, Ariz.

SILVA, M. Morfologia ultra-estrutural do testículo, cinética da espermatogênese e barreira hemato-testicular da tilápia do Nilo, Oreochromis niloticus. (Peixes, Ciclideo). Belo Horizonte: UFMG, 1987. 16p. Tese (Doutorado) - Instituto de Ciências Biológicas - Universidade Federal de Minas Gerais, 1987.

van TIENHOEN, A. 1983. Reproductive physiology of vertebrates. 2.ed. Cornell University Press. p.491. 